Division of Geological \& Geophysical Surveys

MISCELLANEOUS PUBLICATION 135

\title{
ALASKA GAS HYDRATE \\ PLANNING WORKSHOP PROCEEDINGS: \\ Anchorage, Alaska \\ August 17-18, 2005
}

by

Timothy Collett (USGS), Robert F. Swenson (DGGS), and Brenda Pierce (USGS)

December 2005

THIS REPORT HAS NOT BEEN REVIEWED FOR TECHNICAL CONTENT (EXCEPT AS NOTED IN TEXT) OR FOR CONFORMITY TO THE EDITORIAL STANDARDS OF DGGS.

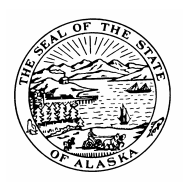

Released by

STATE OF ALASKA DEPARTMENT OF NATURAL RESOURCES

Division of Geological \& Geophysical Surveys 3354 College Rd.

Fairbanks, Alaska 99709-3707 


\section{ALASKA GAS HYDRATE PLANNING WORKSHOP}

\section{-WORKSHOP PROCEEDINGS-}
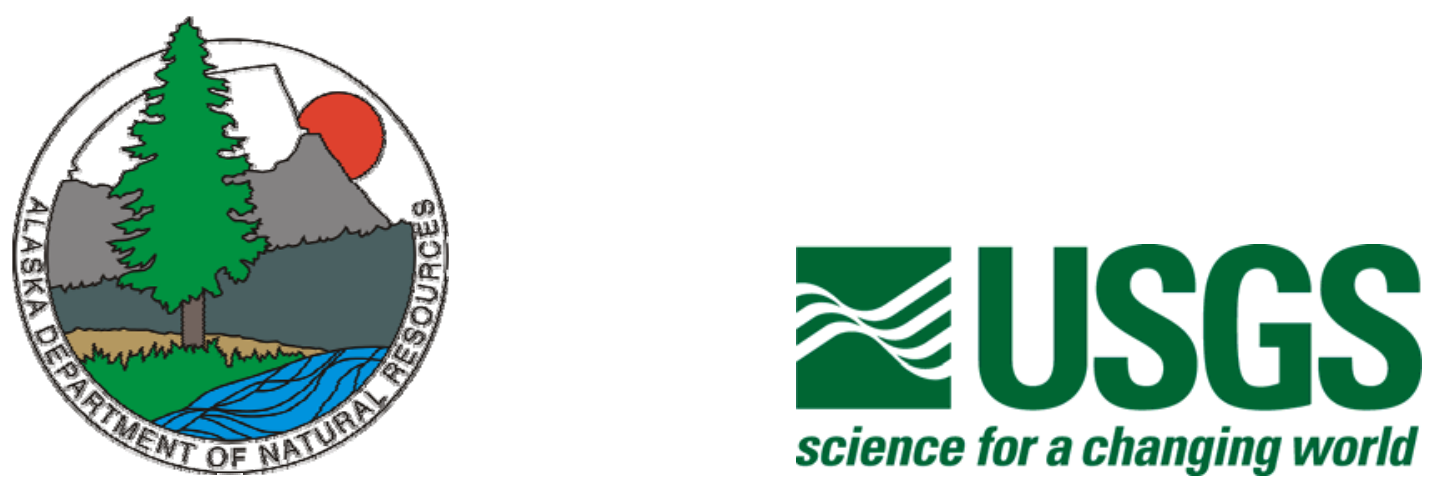

Anchorage, Alaska August 17-18, 2005

Sponsored by

Alaska Department of Natural Resources United States Geological Survey 


\section{ALASKA GAS HYDRATE PLANNING WORKSHOP \\ -WORKSHOP PROCEEDINGS-}

\section{TABLE OF CONTENTS}

I. Executive Summary

II. Recommendations

III. Introduction

IV. Breakout Group 1 - Geological and Engineering Data and Acquisition Evaluation

V. Breakout Group 2 - Gas Hydrate Reservoir Modeling and Production Testing

VI. Breakout Group 3 - Industry Synergies and Opportunities 28

VII. List of Attendees 36

VIII. List of Electronic Presentations 38

Note: Although every effort was made to incorporate all viewpoints put forth in the workshop, the authors acknowledge this summary document of workshop proceedings does not necessarily represent the opinions of all workshop participants or their companies, government agencies, and universities.

Electronic copies of this report and associated presentation material can be found on the following web site http://www.dggs.dnr.state.ak.us/AlaskaGasHydrates.htm 


\section{ALASKA GAS HYDRATE PLANNING WORKSHOP -WORKSHOP PROCEEDINGS-}

\section{EXECUTIVE SUMMARY}

A significant body of gas hydrate research has been developed since 1972 when the world's first gas hydrate test well was drilled on the North Slope of Alaska. The discovery of several large gas hydrate accumulations in the area of the Prudhoe Bay, Kuparuk River and Milne Point oil fields on the North Slope, which may contain as much as 100 trillion cubic feet of in-place gas, have heightened interest in gas hydrates as a potential energy resource. However, none of these gas hydrate accumulations have been adequately tested to determine how much commercially viable gas actually can be produced from the gas hydrates. Further, extraction techniques do not yet exist that have been demonstrated practical for commercial scale production. Although Northern Alaska gas-in-place resource estimates for hydrates are large, hydrates are still an unconventional resource and research is still needed to understand what portion of those resources are technically and economically viable.

On August 17-18, 2005, the Alaska Department of Natural Resources and the U.S. Geological Survey hosted a workshop in Anchorage, Alaska with the primary goal of developing an improved understanding of the energy resource potential of gas hydrates in northern Alaska and identifying the various scenarios for achieving that goal. The workshop was attended by more than 50 participants, representing government, industry, and academic stakeholders in Alaskan hydrates. The workshop included a series of organizational and project review presentations that provided the technical basis for three breakout group discussions. The topical focus of the breakout groups included: (1) geological and engineering data acquisition and evaluation, (2) gas hydrate reservoir modeling and production testing, and (3) industry synergies and opportunities.

The workshop was built on a foundation of previous gas hydrate research, which helped facilitate the workshop discussions. Most of the discussions within the breakout groups focused on the technical and management issues that need to be addressed to move ahead our understanding of the energy resource potential of gas hydrates in northern Alaska. A primary theme recognized was that enhanced cooperation and communication is needed between the various interest groups and organizations in order to fully realize the potential of gas hydrates and to fully 
assess the resource potential. While some participants felt that continued geologic characterization was critical to further research efforts, much input focused on the need to identify economically feasible production techniques in a field setting. The conveners of this workshop have tried to capture and condense the primary issues identified during the workshop into a series of focused recommendations (as included in the next section of this report), but the specifics may not represent the opinions of all the participants.

The workshop recommendations dealt mainly with the development of several interested groups which will be tasked with the responsibility of identifying both technical opportunities and project management synergies that will lead to an understanding of the resource potential of gas hydrates on the Alaska North Slope. The workshop provided a forum for the lively exchange of valuable ideas and opinions, and the workshop conveners greatly appreciate everyone's contributions.

Mark Myers

State Geologist \&

Director, Division of Oil and Gas

Alaska Department of Natural Resources
Brenda Pierce

Program Coordinator

Energy Resources Program

U.S. Geological Survey 


\section{ALASKA GAS HYDRATE PLANNING WORKSHOP -WORKSHOP PROCEEDINGS-}

\section{RECOMMENDATIONS}

1. Develop a 'Producer's Interest Group’ that identifies possible synergies and options to better assess gas hydrate accumulations within applicable production units. This group will be coordinated by an industry representative and will work towards addressing the following issues:

- Identify location and facility access options

- Provide a venue for BPXA to share Phase-1 gas hydrate assessment results with the Prudhoe Bay Unit and Greater Kuparuk Area partners

- Advise the management advisory interest group of possible avenues for intra-unit and industry partnered research opportunities

- Share results of the initial phases of their work with the USGS and the DOE to assess the hydrate resources on the North Slope.

2. Representatives of the DOE, DOI, and Alaska state government and academic institutions form a working group to (1) engage key industry decision-makers to encourage their support/participation for field-based R\&D activities on the North Slope of Alaska, and (2) bring the recommendations of both the technical and industry groups before the hydrate R\&D funding community (particularly the Federal Advisory Committee and the Interagency coordination committee) to ensure ANS gas hydrates have an appropriate role in the federal hydrate R\&D program:

- Reports from the 'Technical Advisory Group' (below) should be incorporated into the planning effort, and prioritized based on the identified goals

- Results from the 'Producer's Interest Group' should be reviewed and incorporated into any research plan

- Identify public education plan to keep public informed of research progress and maintain realistic resource expectations

- Identify multiple options for Alaska gas hydrate research and explore the feasibility of joint industry partnerships, various research collaborations, expansion of the current BPXA project, and identification of various testing location options. 
3. Develop a 'Technical Advisory Group' consisting of representatives from industry, government, and academia capable of developing research guidelines and roadmaps to assess the technical issues needed to determine resource potential of gas hydrates on the Alaska North Slope. At this time it is perceived that this group will be organized by the U.S. Geological Survey, to give non-biased leadership and technical guidance. This advisory group will consist of technical representatives of the known stakeholders in Alaska, with the primary goal to identify options to move an Alaskan gas hydrate research and development plan forward. The 'Technical Advisory Group' would focus on the following:

- Determine what research is required to advance our understanding of gas hydrates in northern Alaska. Results of past and ongoing research efforts, including those of the BPXA-USDOE, BLM-USGS-ADGGS, and Mallik projects, must be used to develop a working understanding of the occurrence of gas hydrates on the North Slope

- Identify the geological/geophysical/geochemical/engineering data required to better understand the occurrence and producibility of gas hydrates

- Develop a plan to gain access to public data and request access to confidential data needed in support of this effort

- Identify potential wells of opportunity to obtain required project data

- Identify the critical components of a dedicated gas hydrate well testing program

- Design the technical aspects of the optimum test holes needed to assess and characterize the production characteristics of various types of gas hydrate accumulations

- Identify technical and environmental issues that current research efforts are not adequately addressing such as permafrost melting, subsidence, lack of voidage replacement, wellbore close approach issues that may prevent drilling shallow gas hydrate wells from existing pads, and so on

- Advise the management interest group on research options and directions 


\section{ALASKA GAS HYDRATE PLANNING WORKSHOP -WORKSHOP PROCEEDINGS-}

\section{INTRODUCTION}

\section{Purpose}

The purpose of this workshop was to review current gas hydrate-related research efforts and to develop both short- and long-term collaborative research plans to help determine the resource potential of Alaska North Slope gas hydrates. In this workshop, the participants identified and defined major technical opportunities that could help achieve a greater understanding of the energy resource potential of gas hydrates in northern Alaska. This workshop was part of the State of Alaska and Federal Government initiative to promote and help facilitate Alaska stakeholder collaboration to assess the resource potential of gas hydrates, and to facilitate the potential production and development of gas hydrate as an economic resource. The workshop results will be used to guide the development of a planning framework for industry, government, and academia collaborative research and development activities.

\section{$\underline{\text { Technical Review }}$}

Gas hydrates are naturally occurring ice-like substances composed of water and gas (mostly methane), in which a solid water-lattice accommodates gas molecules in a cage-like structure. Gas hydrates are widespread in permafrost regions and beneath the sea in sediment of outer continental margins. The amount of gas sequestered in gas hydrates is probably enormous, but estimates of the amounts are highly speculative. Gas hydrates also represent a significant drilling and production hazard. Russian, Canadian, and American researchers have described numerous problems associated with gas hydrates, including well blowouts and casing failures.

The discovery of two large gas hydrate accumulations on the North Slope of Alaska, one along the western edge of the Prudhoe Bay Oil Field and the second overlying the Tarn Oil Field, have established the possibility that gas hydrates may represent an important energy resource for Alaska and the United States. The occurrence of gas hydrates on the North Slope of Alaska was confirmed in 1972 with data from the Northwest Eileen State-2 well located in the Prudhoe Bay Oil 
Field. Most of the gas hydrates near the Eileen discovery well, named the Eileen gas hydrate accumulation, occur in a series of laterally continuous sandstone reservoirs and are geographically restricted to the area overlying the western part of the Prudhoe Bay Oil Field and the eastern part of the Kuparuk River Oil Field. Interpretation of three-dimensional seismic surveys in the Prudhoe Bay Oil Field suggest the presence of free-gas accumulations trapped downdip of several gashydrate-bearing clastic units. The volume of in-place gas within the gas hydrates of the Eileen accumulation is estimated by the USGS to be approximately 37 to 44 trillion cubic feet.

Data from wells along the western margin of the Kuparuk River Oil Field have revealed a large gas hydrate accumulation overlying the Tarn area. The gashydrate-bearing stratigraphic interval in the Tarn gas hydrate accumulation appears to be the up-dip equivalent of the West Sak sands which also contains large volumes of viscous oil. Preliminary analyses of other recently completed wells along the western margin of the Kuparuk River Oil Field suggest that the Tarn gas hydrate accumulation may be larger than the Eileen gas hydrate accumulation.

The volume of gas within gas hydrates estimated within the Prudhoe Bay-Kuparuk River areas may exceed 100 trillion cubic feet of in-place gas. In 1995, the USGS estimated that permafrost-associated gas hydrates across the entire Alaska North Slope may contain between 113 to 590 trillion cubic feet of in-place gas. It is important to note that none of the current Alaska gas hydrate energy assessments have predicted how much gas could be economically produced from these accumulations.

As highlighted, the production potential of the Eileen or Tarn gas hydrate accumulations has not been adequately tested; but it is the present focus of the USDOE-BPXA led industry R\&D gas hydrate research project. Among the various techniques for production of natural gas from gas hydrates from the studies to date, the most promising method is considered to be depressurization. A growing body of evidence suggests that a large volume of natural gas is stored as gas hydrates in northern Alaska. Natural gas production from gas hydrates may be technically feasible; however, numerous technical and commercial challenges must be resolved before this potential resource can be considered an economically producible reserve. Much more work is needed to understand geologic controls on the formation and occurrence of gas hydrates in northern Alaska. In addition, the technology required to economically produce gas from hydrates on a commercial scale must be further developed and tested. 


\section{Workshop Structure}

The organizers identified a series of workshop goals (listed below) for the participants to consider in their discussions. The workshop goals ranged from assessing our understanding of the geologic models for the occurrence of gas hydrates, to identifying the production technologies needed to produce gas hydrates, to the possible development of collaborative research opportunities. To achieve these goals, the workshop included a series of organizational and technical review presentations which are discussed later in this section and included in the appendix of this report. However, the primary feature of the workshop was the convening of three breakout discussion groups, the topical focus of which included: (1) geological and engineering data acquisition and evaluation, (2) gas hydrate reservoir modeling and production testing, and (3) industry synergies and opportunities.

\section{WORKSHOP GOALS}

- Critically examine existing geologic models for the occurrence of gas hydrates. Review present assessments of the energy resource potential of gas hydrates. Examine existing production modeling and testing results.

- Identify and assess the technologies and exploration methods needed to detect gas hydrates and identify potential prospects.

- Identify critical geologic/geophysical data requirements to further assess the volume of natural gas within gas hydrate accumulations and prospects.

- Consider new gas production testing and modeling efforts.

- Identify the potential technologies needed to economically produce gas from gas hydrates.

- Identify potential synergies with other industry opportunities.

- Identify additional organizations interested in working toward a goal of gas hydrate development - Gain Alaska stakeholder collaboration; develop an implementation plan and time-table.

The workshop began with an introduction of the agenda and workshop goals presented by Robert Swenson. Mark Myers completed the introduction by further defining the goals of the workshop (as listed above) and providing the participants with a State of Alaska perspective on the potential development of gas hydrates on the North Slope. Ray Boswell, with the United States Department of Energy (USDOE), provided the workshop participants with a Federal Government perspective on gas hydrate research interest in northern Alaska and included a technical review of ongoing USDOE-supported gas hydrate research efforts in Alaska and elsewhere. The remaining morning presentations dealt mainly with technical reviews of historical and ongoing gas hydrate research efforts in Alaska. 
Tim Collett reviewed the U.S. Geological Survey (USGS) gas hydrate research contributions, and ongoing USGS, Bureau of Land Management (BLM), and Mineral Management Service (MMS) gas hydrate assessment activities. Robert Hunter provided a comprehensive review of the USDOE-BPXA collaborative research effort to characterize resource potential of the Eileen and other gas hydrate accumulations in the area of the Prudhoe Bay, Kuparuk River, and Milne Point oil fields. Shirish Patil concluded the morning session with a review of both historical and ongoing gas hydrate research activities at the University of Alaska, Fairbanks. Web links to electronic copies (pdf files) of the presentations used during the workshop have been included in Section VIII of this report.

Before moving into the afternoon breakout sessions, the organizers provided several key Alaska industry stakeholders with the opportunity to present their perspectives about gas hydrate research and development opportunities. Within this session, Scott Digert provided an overview on the behalf of BPXA and Andre Bouchard represented ConocoPhillips. The organizers also invited Steve Hancock, with APA, to discuss his perspective of the practical petroleum engineering issues that must be dealt with when considering the technical issues associated with the potential economic production and development of gas hydrates. Drawing on his experience as the Mallik 2002 well test project manager, Mr. Hancock was able to compare and contrast conventional gas production concerns with those we may experience with gas hydrates.

As previously mentioned, the primary feature of the workshop was the convening of three breakout discussion groups. Within the breakout groups, the participants actively shared ideas with the support of facilitators. Each breakout group was provided with a preliminary set of questions to help organize and guide the discussions; the use of the questions varied between the breakout groups. In all the breakout groups, however, focused discussion and critical analysis were used to identify needs, challenges, technology opportunities, and to build consensus on possible collaborative actions.

Through the workshop, participants identified:

- Key barriers and issues to meeting the goal of assessing the energy resource potential of gas hydrates in northern Alaska,

- $\quad \mathrm{R} \& D$ opportunities to overcome these issues, and

- $\quad$ Possible action plans, objectives, products, resources and timeframes for potential collaborative opportunities. 
It is expected that this workshop will increase the dialogue between the various gas hydrate stakeholders and interest groups in Alaska and develop strategic collaborations between industry, academia, and government.

The following sections provide the work products of each breakout discussion group. Summary notes are provided along with descriptions of specific barriers and issues, opportunities, and action plans.

\section{Acknowledgments}

The organizers of the workshop would first like to extend their appreciation to all of the participants. The Alaska Department of Natural Resources, through the Alaska Division of Oil and Gas, and the U.S. Geological Survey are acknowledged as the conveners and organizers of this workshop. Special thanks are extended to Dave Nyland for his organization of all the operational and technical aspects of this workshop. Tim Collett (USGS), Bob Hunter (ASRC), and Robert Swenson (ADGGS) also contributed to the organization of this workshop. 


\section{WORKSHOP AGENDA}

Wednesday, August 17, 2005

9:00 a.m. Welcome and Introductions

Robert Swenson, Alaska Division of Geological and Geophysical Surveys

9:05 a.m. $\quad$ Alaskan Government Interests and Workshop Goals

Mark D. Myers, Alaska Division of Oil and Gas

9:40 a.m. $\quad$ U.S. Department of Energy Gas Hydrate Program and Perspective

Ray Boswell, United States Department of Energy

10:00 a.m. Historical Review through Current Programs - Assessments and Prospecting

Tim Collett, U.S. Geological Survey

11:00 a.m. $\quad$ USDOE-BPXA Collaborative Research Project Update - Production Modeling and Resource Evaluation

Robert Hunter, ASRC Energy Services

11:45 a.m. $\quad$ Gas Hydrates Research Review

Shirish Patil, University of Alaska, Fairbanks

12:15 p.m. $\quad$ Lunch

1:30 p.m. Industry Perspectives - Historical Background and Current Interest Scott Digert, British Petroleum Exploration (Alaska)

Andre Bouchard, ConocoPhillips Alaska

Steve Hancock, APA

2:30 p.m. $\quad$ Breakout Sessions

Introduction - Objectives and Directions

Robert Swenson, Alaska Division of Geological and Geophysical Surveys

4:30 p.m. Reconvene General Session - Preliminary Review of Progress

5:00 p.m. $\quad$ Adjourn

Thursday, August 18, 2005

8:30 a.m. Breakout Sessions, Continued

10:30 a.m. Reconvene General Session - Breakout Presentations and Discussion

12:00 p.m. Concluding Remarks and Adjourn the Workshop 


\section{ALASKA GAS HYDRATE PLANNING WORKSHOP -WORKSHOP PROCEEDINGS-}

\section{BREAKOUT GROUP 1 - GEOLOGICAL AND ENGINEERING DATA ACQUISITION AND EVALUATION}

The purpose of the "Geological and Engineering Data - Acquisition and Evaluation" breakout session was first to establish if our understanding of the geological models for the occurrence of gas hydrates were mature enough to make decisions about resource potential of gas hydrates on the Arctic North Slope (ANS). The other major goal of this breakout session was to identify the geological/geophysical/geochemical/engineering data required to better understand the occurrence and producibility of gas hydrates in northern Alaska. Participation in this group included representatives from industry, government, and academia. An attempt was made to use the provided questions (see below) to guide the discussions within this group, but a more systematic scheme of evaluating research data requirements was developed as the group deliberated through the two days of the workshop. The following list summarizes the major concerns of this breakout group:

- Why do we need more data - what do we not know about gas hydrates that is needed to make decisions about their resource potential?

- Is technology development and research related to data acquisition still required?

- What existing well logs, cores, and production data are available in the public domain through AOGCC, MMS, BLM, and others?

- Can wells of opportunity be used to obtain logs, cores, and gas hydrate production data?

- What geophysical data are required to better understand the formation and occurrence of gas hydrates?

- Are dedicated research wells needed to acquire geologic and reservoir engineering data to assess the energy potential of gas hydrates?

Each of these issues are discussed in more detail in the following section of this report. Not all of the discussions within this group are summarized here. These notes have been tailored to address the major issues related to data requirements and availability. 


\section{Group 1 - Geological and Engineering Data \\ Acquisition and Evaluation \\ -Breakout Questions-}

- Are the present geologic/reservoir models for the occurrence of gas hydrate adequate? What is the role of the 'petroleum system' in the formation of gas hydrate accumulations?

- Are published gas hydrate assessment results useful? If not, how can they be improved?

- Are existing gas hydrate exploration techniques adequate? If not, how can they be improved?

- Are ANS hydrate occurrences continuous or patchy? What are the vertical and horizontal extent of the ANS gas hydrate occurrences? Can existing conventional seismic data be used to evaluate gas hydrate accumulations or are optimized high resolution surveys required? Why do we not see BSR seismic features on the ANS?

- What geologic/geophysical/geochemical data is required to better understand the formation and occurrence of gas hydrates?

- What type of industry, government, and academic managed data could be made available to this effort?

- What existing and/or new well logging (NMR, electromagnetic, etc) and geophysical (A VO, velocity inversion, $3 C$, etc) technologies can be used to identify and characterize gas hydrate prospects?

- Is additional petrophysical core data required to further develop our understanding of hydrates? How do natural samples of gas hydrates differ from laboratory grown samples?

- Do we understand the nature of gas hydrate occurrence at the pore scale? What are affects of pore water salts, pore size variations, gas chemistry, etc?

- Why do we need more data - what do we not know about gas hydrates that is needed to make decision about their resource potential?

It was generally accepted that there has been significant advancements in our understanding of the geologic/reservoir models for the occurrence of gas hydrates in Arctic environments. The results of the previous USGS-USDOE work in northern Alaska and the multinational Mallik project in Canada were cited as significant contributions. It was also acknowledged that the concept of a gas hydrate petroleum system approach (source-migration-reservoir-trap-timing) to study the occurrence of gas hydrates was with merit. It was also recognized that certain aspects of marine versus on-shore Arctic gas hydrate accumulations may be 
fundamentally different, with an important consideration being the concentration of high quality reservoir rocks in a relatively accessible area.

For the most part, this group concluded that more work is required to make critical resource decisions about the occurrence and producibility of gas hydrates on the ANS. It was generally accepted, however, that more is known about the occurrence of gas hydrates than their sustained economic production. Many in the group agreed that it is important to assess the geologic complexity of these known gas hydrate accumulations, and identify suitable drill sites to test gas hydrate production technologies. Because there was some concern about the criteria used to select potential test sites, it was suggested that additional integrated geologic and production modeling studies were needed to identify the characteristics of suitable test sites. Others in the group felt that rather than additional geologic characterization, gas hydrates must be tested and produced at sufficient rates to convince individuals that hydrates will become a viable energy source.

\section{- Is technology development and research related to data acquisition still required?}

For the most part, it appears that the technologies developed for the study and characterization of conventional oil and gas resources can be applied to the analysis of the energy resource potential of gas hydrates. It can be concluded that future research should be focused mainly on technology utilization - not tool development. The research areas include: (1) well log analysis, (2) seismic technology development (amplitude analysis, velocity conversion, multicomponent data, amplitude-versus-offset analysis, etc.), (3) development of electromagnetic survey methods, and (4) the development of production testing equipment and methods. Integrated laboratory-field-modeling studies will be required to advance our understanding of the technologies needed to assess the resource potential of gas hydrates.

\section{- What existing well logs, cores, and production data are available in the public domain through AOGCC, MMS, BLM, and others?}

In most cases, well data (including logs, core analysis, and production test results) are systematically released to the public in Alaska 25-months after completing the well. In most all cases, however, the economic targets for these wells are deeper 
than the overlying gas-hydrate-bearing interval. The gas-hydrate-bearing section in most wells is not logged, or the quality of the acquired log data is inferior in these shallower sections. There also have been very few shallow cores or production tests performed on the ANS. The only exceptions have been the cores and limited tests conducted in the Northwest Eileen State-2 well, the high quality core recovered from the Hot Ice well, and the deeper West Sak, Schrader Bluffs, and Ugnu cores.

\section{- Can wells of opportunity be used to obtain logs, cores, and gas hydrate production data?}

Within the USGS-USDOE and the BPXA-USDOE projects, special wells of opportunity, being drilled for deeper targets, have been the focus of expanded logging programs. Conventional wireline logging and logging while drilling (LWD) data (including resistivity, acoustic Vp-Vs, neutron-density porosity, NMR, VSP, and gas mud temperature logging) from these special opportunities have contributed to our understanding of the gas hydrate occurrences on ANS. It was noted that the acquisition of acoustic LWD data can be problematic due to the slow velocity of these shallow sediments. This breakout group also concluded that wells of opportunity, which might include drilling development/delineation/exploration wells, recently completed (cased) wells, and older wells going out of service, could be used to acquire log data, cores from the overlying gas hydrate section and/or limited production testing data. However, this discussion group did recognize that any operation in a well represents a potential risk to the operators and a delay in completing the well. An additional conventional wireline log run will add both time and risk to a drilling project. It is possible that LWD operations could help overcome some of the problems associated with conventional wireline logging. It was highlighted that older wells in decline and scheduled for abandonment could represent favorable wells of opportunity for additional logging and production testing. However, the mechanical condition of these older wells may not be suitable for gas hydrate testing. It is also possible that some gas hydrate testing could be added to the end of an exploratory well before abandonment.

The group concluded that in some cases the risk and cost associated with the acquisition of gas hydrate related data could be justified if the operators were able to see a cost-benefit of the proposed effort. A proponent would need to document benefits of acquiring data for other projects, such as Ugnu data, seismic time-depth models, and/or need to know more about gas hydrates as a drilling hazard. A company may also find support from other parts of the company. Wells of 
opportunity could provide insight into the historical impact of gas hydrate related drilling problems and the development of a best practices approach for drilling gas hydrates. The proponents would need to work with appropriate groups to inventory and recognize opportunities relative to other business activities, similar to the historical MPU S-pad and I-pad, and Tarn gas hydrate logging efforts.

\section{- What geophysical data are required to better understand the formation and occurrence of gas hydrates?}

Within the BLM-USGS-ADGGS and the BPXA-USDOE projects, 2D and 3D seismic data have been used to identify and map the distribution of gas hydrates over the Milne Point Oil Field. It was agreed within this breakout group that more work was required to understand the occurrence and distribution of gas hydrates at a prospect scale for other areas on the ANS. All of the 2D/3D seismic data for the area of Eileen and Tarn gas hydrate accumulations have been collected for other more conventional oil and gas exploration and development purposes. In most all cases, these data are owned by industry and are held confidential. Most of the existing 2D/3D seismic data from the areas of interest were acquired at great financial cost and the owners are naturally resistant to releasing these data. There have been a few notable exceptions where released industry 2D/3D seismic data have proven to be a useful tool to assess the occurrence of gas hydrates. But in many cases the acquisition parameters and processing of these surveys have greatly diminished the quality of the shallower portions of these data sets. In some cases it has been possible to obtain a public release of the upper shallower portion of surveys to assess potential hydrate occurrences, but the data are often of inferior quality.

Much like the discussion about wells of opportunity, this breakout group concluded that in some cases the seismic data owners might be willing to release appropriate seismic data if the operators were able to see a cost-benefit of the proposed seismic data release. A proponent would need to document benefits justifying the release of the needed 2D/3D seismic data. For example, what would be the benefit of this data release to other projects (i.e., Ugnu data), or the improvement of time depth models, and/or need to know more about gas hydrates as a drilling hazard? The proponents would need to work with appropriate groups to inventory available 2D/3D seismic data sources. It is important to note that this work could also be conducted within the companies under traditional confidentiality agreements. The gas hydrate project proponents should also 
consider contributing to proposed seismic surveys, which could be augmented to acquire data more suitable for gas hydrate assessment. This breakout group also concluded, however, that there was not much justification for conducting dedicated gas hydrate 2D/3D surveys at this time in the main Prudhoe Bay production complex.

\section{- Are dedicated research wells needed to acquire geologic and reservoir engineering data to assess the energy potential of gas hydrates?}

Breakout Group 2, which dealt with gas hydrate reservoir modeling and production testing issues, concluded that dedicated production testing is required to further assess the production response of gas hydrates to various productions schemes. Breakout Group 1, also felt that this issue fell in its area of interest when considering what type of geologic or engineering data would be acquired in a dedicated gas hydrate test well.

Group 1 concluded that a dedicated test well or wells would be needed to obtain some of the more critical geologic and engineering data required to assess the resource potential of gas hydrates on the North Slope. A dedicated test well would provide for the release of much needed public data, probably from a State lease. Some of the benefits of a dedicated test well include the fact that it would be fit-topurpose, specifically sited for gas hydrate testing, would have limited impact on other business interests, could have multi completions, and could be used to conduct many integrated tests. On the negative side, dedicated wells are often more costly; for example with the Hot Ice project at \$15M USD and the Mallik 2002 project at \$17M USD. However, drilling from existing gravel pads and making use of existing infrastructure could significantly reduce the cost of dedicated test wells.

It was recognized by this group that the primary gas hydrate targets in the Eileen area are at a depth of less than 3,000 ft. The area of the Eileen gas hydrate accumulation (which lies within the Prudhoe Bay, Kuparuk River, and Milne Point units) has roads/pads (gravel) and facilities for gas/water handling. 
Listed below are the primary components necessary for a dedicated gas hydrate test well:

\section{Site Selection:}

Pre-site evaluation, consisting of reviewing existing well and seismic data for test design. Some locations may require additional confirmation and data acquisition (drilling and seismic data).

\section{Operations:}

Would probably require a mud chiller and an advanced mud chemistry program, standard and research mud gas logging, and a mud chiller may enable a conventional well logging program.

\section{Needed Reservoir Data:}

Reservoir porosities and gas hydrate occurrence-distribution-saturations at various scales. Mass and heat flow measurements, such as sediment permeabilities and fluid composition. Rock mechanics measurements as a function of gas hydrate content and relative change during production.

\section{Well Log data:}

Well log data measurements should include resistivity, acoustic Vp-Vs, neutrondensity porosity, NMR, electromagnetic, image logs and drilling mud gas and temperature logging. Both conventional wireline and LWD logging should be considered. The addition of a VSP survey is strongly recommended. Also smart well completions (with DTS, pressure, resistivity, and acoustic sensors) should be considered along with compaction monitoring. Under this discussion we have also included limited formation testing and wireline testing such as MDT and RFT, with downhole fluid analyzer.

\section{Cores:}

The utility of conventional and pressure coring needs to be compared and contrasted. For the most part, conventional coring in gas hydrates have yielded unsatisfactory results. Pressure core systems have the potential of yielding more pristine, and therefore more representative, cores. However, pressure coring still needs further engineering development. When possible, consider continuous coring with systems compatible with more advanced pressure core systems. Also consider dedicated pilot log holes with side track core holes (vertical) to help guide the coring program. Required core measurements would include a very long list which should also include integrated lab-core experiments. Special hydrate 
laboratory measurements should include X-ray scans, NMR, XRD, resistivity, acoustic, etc.

Shot-Term Testing (petrophysical):

Pressure testing and petrophysical tools both wireline and LWD deployed.

Long-Term Testing:

Critical production data include rates, volumes, and fluid composition. See Group

2 breakout discussion in this report for more recommendations on production testing. 


\section{ALASKA GAS HYDRATE PLANNING WORKSHOP -WORKSHOP PROCEEDINGS-}

\section{BREAKOUT GROUP 2 - GAS HYDRATE RESERVOIR MODELING AND PRODUCTION TESTING}

The purpose of the "Gas Hydrate Reservoir Modeling and Production Testing" breakout session was to determine what additional gas hydrate production testing and modeling are required to assess the resource potential of gas hydrates on the Arctic North Slope (ANS). Much like Breakout Group 1, participation in this group included representatives from industry, government, and academia. This group worked closely with the provided questions (see below) to guide the discussions; however, the notes from this session have been grouped into the following seven major concerns:

- What is the status of current gas hydrate modeling testing research efforts?

- What additional laboratory studies are needed to further characterize the energy resource potential of gas hydrates? Are additional laboratory studies needed to develop and calibrate existing production models?

- What existing and new technologies (i.e., drilling, completion, secondary stimulation - thermal, $\mathrm{CO}_{2}$, bacterial, etc.) could potentially be applied to the production of gas hydrate?

- How should a gas hydrate production testing research program be structured?

- Is additional production testing needed to verify existing production models? What type of testing should be considered? What type of data needs to be collected from future production tests?

- What environmental issues are associated with gas hydrate production?

- Cooperation is needed between the various groups and organizations involved in assessing the resource potential of gas hydrates in Alaska and elsewhere.

Each of these issues are discussed in more detail in the following section. 


\section{Group 2 - Gas Hydrate Reservoir Modeling And Production Testing -Breakout Questions-}

- What have we learned from existing production testing and modeling results? What additional work needs to be done? How can they be improved?

- Are additional laboratory studies needed to develop and calibrate existing production models?

- In comparison, what are the advantages and disadvantages of the existing gas hydrate production models? Is there a need for a code comparison study?

- What existing and new technologies (i.e., drilling, completion, secondary stimulation - thermal, $\mathrm{CO}_{2}$, bacterial, etc.) could potentially be applied to the production of gas hydrate?

- Is additional production testing needed to verify existing production models? What type of testing should be considered? What type of data needs to be collected from future production test?

- Can we apply conventional economic models to further our understanding of gas hydrate production?

- What characteristics of hydrates or hydrate-formation matrices will be limiting to production, e.g., permeability, heat transfer?

- What type of data is needed to understanding the movement of fluids (water and gas) in a hydrate-bearing reservoir? Where does gas hydrate occur in a porous media and how does it affect reservoir permeabilities?

- Can we identify candidate hydrate sites for additional geological/geophysical data acquisition and production testing? Should future testing be focused on the gas hydrate only and/or the underlying free-gas accumulations?

- What are the potential problems associated with co-produced water? What are the environmental issues associated with water disposal?

- What is the status of current gas hydrate modeling testing research efforts?

To gain a better understanding of the production capability of a gas-hydratebearing reservoir, it is imperative to have adequate models which can predict relative permeability and movement of fluids within the reservoir. Existing models (i.e., Tough-Fx, CMG-STARS, and others) have been validated using only 120 hours of actual field data. The primary function of these models has been to simulate the behavior of hydrate reservoirs in an effort to anticipate production methods and strategies. The simulations have focused on thermal stimulation and 
depressurization to dissociate the gas hydrate. However, general consensus is that more physical measurements and data gathering are necessary in order to validate the models over a commercially significant production period.

Some very fundamental aspects of modeling have yet to be worked out (i.e., relative permeability and porosity). Evidence also exists that first order rate equations currently in use to model dissociation are poorly constrained. Two models that utilized the Mallik 2002 test well data (temperature, porosity and pressure, etc) resulted in very different simulated production rates; one model showed steady decline after a long period of relatively low production, whereas the other model predicted a period of quick decline after an initial high rate of production.

Although accurate production simulation through modeling is critical, extended field testing and data gathering are extremely important to establish calibration parameters. Currently, the models being developed and employed are challenged by a lack of physical data. It was suggested that a wide range of measurements from multiple testing scenarios is necessary to refine the modeling effort and substantiate the simulated results. Although no significant gas hydrate well production testing has been conducted to date, there has been important information gathered from recent operations (Mallik 2002 and others).

Using MDT experiments, which were designed to look at the effects of depressurization, Mallik researchers were able to determine that gas hydrates are not solid masses and exhibit permeability. Also, gas hydrate dissociation was found to extend out away from the wellbore farther than expected. Although original hypotheses were not always substantiated (i.e. permeability and other unexpected 'complications'), the Mallik 2002 team was able to effectively control and modify the testing procedures on site. The knowledge gained from the Mallik 2002 project suggests that much more field experimentation is needed to better understand gas hydrate reservoir systems.

It was suggested that the next logical step would be to initiate testing on a reservoir scale, rather than a well scale. This is necessary in order to obtain a better fieldscale response; to establish and observe trends in reservoir pressure, dissociation, and thermal properties; and to perform actual production testing. 


\section{- What additional laboratory studies are needed to further characterize}

the energy resource potential of gas hydrates? Are additional laboratory studies needed to develop and calibrate existing production models?

A significant shortfall in laboratory testing of gas hydrates is the lack of pristine, naturally formed samples. Although gas hydrate cores can be brought up to the surface (by the ODP and other methods), there can be as much as $50 \%$ of the initial gas hydrate lost through dissociation. There is also limited understanding of the effects of gas hydrate storage and preservation techniques on the recovered natural samples.

Although gas hydrates have been created in the laboratory, there remains concern regarding comparison of these samples with naturally occurring gas hydrates. For example, the length of time it takes for gas hydrates to form in nature is poorly understood and cannot be easily simulated in the lab. Additionally, creating a pure gas hydrate without left over gas or water in the sample has been very challenging.

The use of CT and other scanning methods have proven important in understanding the behavior of gas hydrates dissociation. Recent UAF laboratory data on synthetic gas hydrate samples have indicated that with increasing gas hydrate saturations, gas-water relative permeability tends to decrease. Additional tests are needed to define the relationship between relative permeabilities and gas hydrate saturations.

Other tests have been run on laboratory-formed gas hydrates to assess the fluid mobility of gas and water in gas hydrate systems. Fluids in gas-hydrate-bearing reservoirs are generally considered immobile; however, some recent lab studies have indicated that fluid mobility may increase with increases in the fluid phase volume. Additional laboratory and physical tests need to be conducted to better understand these phenomena.

It was suggested that a combination of laboratory and production testing research into one facility would greatly enhance our ability to further address the characterization of gas hydrates. 
- What existing and new technologies (i.e., drilling, completion, secondary stimulation - thermal, $\mathrm{CO}_{2}$, bacterial, etc.) could potentially be applied to the production of gas hydrate?

Experimental technology that could potentially be applied to gas hydrate production tests include those which are being simulated in current modeling efforts (thermal dissociation etc.), as well as $\mathrm{CO}_{2}$ injection and depressurization. Without having production test data available, however, current laboratory experiments can not provide accurate predictions of what techniques would work in complex wellbore environments.

\section{- How should a gas hydrate production testing research program be structured?}

It was suggested that production testing should be seen more as an industry test, rather than a scientific project. It is possible that the two should be combined, allowing both objectives to be pursued. For example, resource delineation of gas hydrates could be viewed as an industry exploration process, with numerous well bores defining an accumulation. This could be beneficial for both well testing purposes and longer term second phase production testing. However, it was pointed out that firm cost/benefit information will be necessary to make a compelling case for industry. To that end, the USDOE has been authorized funds to promote research and partner with companies to investigate this potential resource. At this point, it remains unclear whether USDOE will be allocated funding, and if so, how will USDOE funds be made available and/or how it will be spent. Other funding opportunities may also be possible in the form of industry exploration funds and international ventures (e.g., Japan, India, and Korea). These potential investors may be interested partnering in order to gain critical knowledge that might be developed by research on the North Slope of Alaska.

Economic analysis would also be an important aspect of any program. Clearly, business decisions are very challenging without sufficient research data to incorporate in economic models. Production testing should be conducted to test the various models and provide viable rate scenarios that can be incorporated in commercial decisions. With regards to applying conventional economic models to production testing, it would depend primarily on whether gas hydrates are considered a realistic resource. 
A systems type (network) economic analysis approach would likely be beneficial in motivating industry to participate in a viable research program. Obviously, if commercial expectations are created and then not achieved, companies would incur losses and be less likely to pursue further gas hydrate research. Alternatively, it may be advantageous to prove production technology at a limited scale operation in order to prove gas hydrate producibility. Perhaps this could be done at an existing well, but there are many complications when sharing a pad and/or existing borehole with conventional production. To this end, it would perhaps be more beneficial to spend the money necessary to drill dedicated research production test wells, with dedicated facilities and staff.

\section{- Is additional production testing needed to verify existing production models? What type of testing should be considered? What type of data needs to be collected from future production tests?}

There appears to be many different types of gas hydrate occurrences on the ANS ranging from gas hydrate only reservoirs to gas hydrate accumulations underlain by free-gas. While gas hydrate accumulations underlain by free-gas may be the most desirable economically, the primary focus during production testing should be on the gas hydrates themselves. This would facilitate a better understanding of how to produce gas from gas hydrates alone or in association with free-gas. In other words, if the overall goal is to assess the long-term productive potential of the gas hydrates (under various production schemes), it is more important to understand how gas hydrates will behave as a gas-bearing reservoir.

There is some question about the type of gas hydrate accumulation which should be tested first. For example, it may be helpful to focus on a thick layer of gas hydrate in order have easier access for testing, and acquire a better understanding on the effects of large scale dissociation of reservoirs. However, arguments can be made that the typical North Slope accumulation would remain untested, and a portion of the program should be focused on accumulations that are more difficult to reach and define.

There are other constraints to consider in regards to facilities during a gas hydrate production test. In the Prudhoe Bay, Kuparuk River, and Milne Point infrastructure areas, limitations exist on the amount of gas and produced water that can be handled in nearby facilities. Alternative options for the gas could include: (1) using production to help power facilities, (2) piping small amounts to other 
facilities for re-injection into viscous oil reservoirs, or (3) flaring the produced gas during short-term tests. What options to pursue would obviously depend on what production rate and test duration is expected during the operation, and what local facilities are available.

Additionally, oil and gas operations on the Alaska North Slope are challenged by operational time constraints. The drilling season can be cut critically short because of weather conditions and surface thawing, and is typically limited to late December thru early May. Also, if production test drilling is done during the normal winter drilling season, rig availability may become an issue as most of the drilling rigs are committed to existing conventional oil and gas projects.

There was significant discussion on whether preexisting facilities (both in-use and abandoned sites) or a new dedicated facility would be more desirable. Several existing facilities provide some benefits for gas hydrate production testing. The Prudhoe Bay Unit L-Pad is one site which has been considered favorable in terms of location and geologic evidence of gas hydrate occurrence. Within the Eileen trend, there are unused gravel pads which could limit impact on other operations while allowing reasonable access to facilities. However, from a research perspective, it was suggested that considerable advantages are gained by being separated from conventional production activities, and the possibility of using unconventional methods such as platforms, should be strongly considered. Unconventional methods would extend the operation-window and make yearround drilling and well testing feasible.

A raised arctic platform was constructed by an Anadarko-led consortium during the Hot Ice research project in 2003. This platform was specifically designed to limit the environmental impact of drilling in permafrost areas and extend the drilling season. However, a full-scale production project would likely require larger permanent facilities.

Objectives for a test well should be separated into two main categories: (1) primary production, and (2) recovery methods such as $\mathrm{CO}_{2}$ sequestration and other more experimental and complicated techniques. It was argued that testing should be started as a field laboratory experiment, yet retain flexibility to move on to more complex stages (and gain additional information and understanding) as the project advances. Experiments such as $\mathrm{CO}_{2}$ injection to stimulate dissociation should clearly be tested, however proving commercial production by other, more conventional methods may prove to be critical in the early phases. 
It was generally agreed that:

- The main objective of field production tests should be for gathering data on rate, completion design, relative permeability, pressure response, and the thermal and mechanical properties of dissociating gas hydrates.

- It would be beneficial to have a platform or gravel pad to test multiple production concepts in the longer term (6 months to several years, if possible). This would also provide opportunities for model validation.

- Production testing could be optimized by testing in an area where longer tests can be conducted; rather than obtaining only preliminary testing data. A gas hydrate production testing facility, rather than a single, in-field test well, may be necessary to achieve long-term testing and data acquisition requirements.

- Simple completions, such as vertical wells, should initially be pursued to provide critical reservoir data. However, horizontal production test wells with equipment (fiber optics) to monitor pressure and other responses should be undertaken during the program. It is important to determine production capabilities under multiple scenarios.

\section{- What environmental issues are associated with gas hydrate production?}

Produced water is a significant issue for a gas hydrate production test. Existing gas hydrate production models suggest that a gas hydrate well producing 2-3 mcfpd of gas would also produce 1,000-3,000 barrels of water per day. Some options for water handling include: (1) a disposal well on site (which is difficult because the water is very clean and may not be compatible for injection into existing deeper oil reservoir systems), (2) using the fresh water to build ice roads in the winter, (3) using the water for dust control on gravel roads in the summer or (4) piping to other facilities. Surface disposal would be the least expensive, but current regulations on produced water would need to be addressed.

Producing water from a gas hydrate test well could be done by gas lift, but injected gas volumes must be closely monitored. Progressive cavity pumps (PCP) would also work, and be less expensive since gas hydrate accumulations on the ANS occur at $2700 \mathrm{ft}$ or less. PCP's can also handle expected sand production. Water well and coal bed methane technologies should be considered since these completions would be more analogous (in terms of depths and pressures 
encountered) than conventional oil and gas drilling technology. Technical issues also exist with regards to drilling a well directly under the pad, and what (if any) special considerations must be made due to the relatively shallow depth of onshore gas hydrate accumulations. It would be helpful to have an interdisciplinary committee look into the different strategies for disposal of water produced from gas hydrates.

\section{- Cooperation is needed between the various groups and organizations involved in assessing the resource potential of gas hydrates in Alaska and elsewhere.}

It was fully agreed that knowledge sharing is necessary to optimize a production research effort. There are many organizations in industry, academia, government, and other countries that are conducting similar experimentation. In some cases, results from these studies have been made public and are easily assessable, yet data from other projects remain confidential. Every effort should be made to move critical data and information into the public domain. Obviously, running similar experiments can be beneficial, yet with proper communication, the data gained could be complementary rather than redundant. It seems critically important to have an open exchange of information between industry representatives, academia and other countries in order to maximize knowledge gained and minimize repetition of effort. 


\section{ALASKA GAS HYDRATE PLANNING WORKSHOP -WORKSHOP PROCEEDINGS-}

\section{BREAKOUT GROUP 3 - INDUSTRY SYNERGIES AND OPPORTUNITIES}

Breakout session 3 was undertaken in an attempt to outline the synergies and possible collaboration that should be an integral part of a comprehensive gas hydrate research program in Alaska. Numerous detailed studies have been completed in the North Slope region, and this research lays the groundwork for the next phase in defining the resource potential. Additionally, the operational and economic importance of access to modern infrastructure cannot be underestimated if we are to maximize critical data gathering. It will be important to take advantage of existing knowledge and operational expertise when outlining a detailed research effort. A common underlying theme of the discussions was that quantifying current completion and production models is critical to advancing towards a goal of developing natural gas hydrates as a viable energy resource.

This breakout session had representatives from many of the stakeholder groups including UAF, ISER, ASRC, USDOE, BPXA, CPAI, EXXON, BLM, AOGCC, ADOG, ADGGS, USGS and others. An attempt was made to identify key questions from the list provided (see below) and given the diversity of attendee's backgrounds, the results could be considered relatively focused. It was the general consensus that many of the questions provided were interrelated and could be combined to a few key issues. The following list is a summary of those key components.

- What are the key components in a comprehensive research program?

- Is there really a prize? When will the prize be realized?

- What synergies are available for stakeholders to benefit?

- How can both short-term and long-term goals be met under the same program?

- How do we stimulate activity in hydrate research and development?

- How do we develop a viable, comprehensive research effort prior to proving commercial viability? 


\section{Group 3 - Industry Synergies and Opportunities -Breakout Questions-}

- Gas hydrates are often described as a big pay-off but high risk opportunity, with any potential pay-off far off into the future. What type of project partnership might be able to deal with this complex opportunity?

- What are some of the industry synergies that could contribute to the potential production of gas hydrates? Could the produced gas and water from hydrates be used for other industry applications on the ANS? Are there synergies for the coproduction of hydrates with conventional oil and gas on the ANS?

- What have been the benefits and drawbacks of historical industry, government, and academic cooperative projects?

- What can government do to facilitate our understanding of the resource potential of gas hydrates?

- Which industry, government, and academic organizations could contribute to developing our understanding of the energy resource potential of gas hydrates?

- What is the potential time table for implementing cooperative research and development opportunities?

- Are there examples of business models for the development of other unconventional resources that can be applied to gas hydrates?

- Of the currently identified hydrate accumulations, which ones show the greatest promise of near term testing programs using existing infrastructure.

- How can all current Alaska stakeholders benefit from a collaborative research effort and access to critical data.

Not all of the discussions that were undertaken will be covered here, however, there is an attempt to address all the concerns and ideas that were put forth. The first day of the breakout was focused on input related to the key questions, whereas the second day focused on the key components of assembling a viable research program, and in identifying a list of action items to help bring that research program to the next step.

- What are the key components in a comprehensive research program?

There was nearly unanimous agreement among the participants that previous work done in Alaska, and outlined in the presentations earlier that day, represents a critical body of work that should be utilized as the basis for identifying the next phase of development. Identification of the resource potential and baseline understanding of the opportunities has been fairly well documented. It was very clear that the USDOE funded work performed by BPXA and others should be 
incorporated in the overall strategy for the way forward. The following list identifies the main topics of discussion on this question:

- Identify all Stakeholders

- Identify a management group to outline goals and help focus Alaskan gas hydrates research

- Provide continuity to help avoid research overlap

- Provide information to help develop and focus research proposals

- Address industry buy-in at high levels

- Address government buy-in at high levels

- Identify properly scoped options

- Populate a technical advisory group to identify key research avenues and provide a research guide for management group

- Include all current stakeholders where applicable

- Identify common goals

- Build on current work

- Provide access to existing data

- Identify a focused research vision and plan

- Identify options for testing key research questions

- Practical application of technology is key

- Keep multiple options open, and explore the feasibility of the following:

- Joint Industry Partnership

- State/Federal/Private collaboration

- Expand on current BPXA project

- Options for testing location

- Currently leased land

- State land not leased

- Borough / privately owned land

- Native corporation lands

- Timing

- Why Now?

- Level of work and funding needed to advance to next step

- Time line critical for key decisions

- Gas sales/ local use potential

- Need for integrated team (field to lab) with appropriate champions

- Identify education opportunities in an attempt to bolster current research effort and continue development of the research effort in the long term

- Graduate research opportunities at various institutions

- Identify and train new scientists to carry research forward

- Continuity of funding 
- Difficulty of planning when yearly renewed appropriations are sole source

- Appropriate level of funding

- Is current level sufficient to test the viability of this resource in Alaska?

\section{- Is there really a prize? When will the prize be realized?}

There was a fair amount of discussion surrounding this issue. Nearly all participants recognized that significant in-place resource exists, and is fairly well documented in areas of high data density. However, there remains a need to continue characterization of hydrate accumulations across the North Slope and attempt to further quantify the resource potential. Nevertheless, without a significant effort on production research and testing, understanding what the 'prize' is, may be unattainable. Clearly, the argument lends towards a 'chickenand-egg' predicament if production testing and research is held off until economic viability is identified. Given our current understanding and available technology, production testing is paramount in demonstrating that an economic resource is attainable in the short term. Like any unconventional resource, acquiring baseline data will be necessary to truly identify when commercialization may become a reality.

- What synergies are available for stakeholders to benefit?

- How do we stimulate activity in hydrate research and development?

Not all the possible synergies discussed are currently available, yet most agreed the following list would be important for moving forward.

- Government Funding

- Long-term continuity at appropriate funding levels

- Incentives

- Some incentives exist, but most incentives are focused on conventional resource development and production

- It is important to share the 'burden' of any research developments

- Include all stakeholders in discussions on potential impacts

- Possibly develop a joint industry partnership 
- Negotiate adequate funding; in cash or in kind

- Identify near term use for gas

- Local fuel consumption, pressure support, local sales, etc.

- Identify near term use for developed technology

- Including other non-conventional resource applications

- Increase and/or balance long-term vs. short-term benefits

- Identify synergies with current production operations

- Minimize impact on current operations

- Streamline regulations

- Provide potential options for marketing the resource worldwide

- Provide avenue for sharing pertinent data

- How can both short-term and long-term goals be met under the same program?

This question is relatively complex given the variable agendas each of the participants works under, and is also interrelated with the question of "what is the prize" discussed above. While the producers are primarily focused on maximizing current production of conventional reserves, industry, governmental and academic researchers focus on long-term commercialization testing and identification of a potential resource that may ultimately benefit a broad scope of participants over the long term. Regardless of a given agenda, it is clearly in the best interest of all concerned to identify how this potential resource fits within their specific portfolio and what plan of action (or inaction) is appropriate. The following bullets encompass the discussion points.

- Identify local gas use

- Develop technology that has broader, immediate application

- Minimize impact to current operations

- Incorporate testing program with conventional operations

- Develop a time line that is synergistic with current operations

- Develop a model for using dry gas as replacement for wet associated gas

- Identify business needs outside of unit boundaries

- Keep short and long term goals separate, but concurrent in pursuit 


\section{- How do we develop a viable, comprehensive research effort prior to proving commercial viability?}

Although this question may seem benign, it again points out a potential rift between research partners. In fact, a 'comprehensive' research effort must include proving commercial viability (again, a chicken-and-egg argument). Clearly the risk and burden must be spread reasonably across all stakeholders if there is to be any agreement on how the effort proceeds. However, the benefit must likewise be distributed in the many forms benefit is realized. Open communication among all stakeholders will remain critical if a 'comprehensive' research effort is to be pursued.

The remainder of the breakout session was focused on identifying real and perceived problems associated with continuation of this research, and possible solutions that should be considered during development of the next step. The conclusion of the session brought out a list of action items that would be pursued over the coming months to address all the issues and firm up solutions to the identified common goals.

- Potential problem areas towards achieving research goals

- Industry concerns

- Distraction Factor

- Facility constraint

- Personnel

- Safety

- Data Access

- Cost Vs. Benefits

- Partner Alignment

- Oversight by $3^{\text {rd }}$ parties

- $\mathrm{Pad} /$ space/rig availability

- Researchers/Government concerns

- Data and Facility Access

- Personnel

- Continuity/longevity of funding 
- Potential Solutions

- Develop a screening/oversight team

- Develop a project that maximizes the number of stakeholders involved

- Identify appropriate location(s) for program efforts

- Identify appropriate technologies to be incorporated in both production and research effort

- Optimize project plan

- Identify options for secure, long-term funding

\section{Action Items}

- Identify an ad hoc working group to engage industry leaders in advancing R\&D opportunities in Alaska (Ray Boswell, Lead, USDOE)

- Include representation from:

- Industry

- Federal

- State

- University

- North Slope Borough

- Etc.

- Hold industry discussion sessions (Don Ince, Lead, CPAI)

- Identify location and facility access options

- BPXA to share stage 1 DSP with PBU and GKA partners

- Identify key industry personnel for advancing hydrates research and testing efforts

- Identify public education plan (Fran Ulmer, Lead, ISER.)

- Develop a technical advisory committee (Tim Collett, Lead, USGS)

- USGS led group of stakeholders and research entities

- Identify all options available to move research plan forward

Overall, the breakout session was a great success. There were numerous positive comments provided following the work session that indicated optimism for moving forward. Clearly there is need for many more discussions and work sessions to 
move on the initiatives and identify participants. However, communication was clearly initiated and progress was made. All action item leaders should currently report progress to Ray Boswell, and ultimately to the interest group being defined above. 


\title{
ALASKA GAS HYDRATE PLANNING WORKSHOP -WORKSHOP PROCEEDINGS-
}

\author{
VII. LIST OF ATTENDEES
}

2005 Alaska Hydrate Workshop Participants

\begin{tabular}{|c|c|c|c|c|}
\hline Name & Organization & Email Address & Phone & Group \\
\hline Warren Agena & United States Geological Survey & wagena@usgs.gov & (303) 236-5751 & 1 \\
\hline Sunny Aguilar & Alaska - Division of Oil and Gas & ssa.dnr.state.ak.us & (907) 269-8707 & 3 \\
\hline Ray Boswell & Department of Energy & RAY.BOSWELL@netl.doe.gov & (304) 285-4541 & 3 \\
\hline Andre Bouchard & CPAI (Anchorage) & Andre.J.Bouchard@conocophillips.com & (907) 265-6036 & 3 \\
\hline Bob Casavant & University of Arizona & casavant@geo.arizona.edu & (520) 626-3785 & 3 \\
\hline Tim Collett & United States Geological Survey & tcollett@usgs.gov & (303) 236-5731 & 1 \\
\hline Scott Cooley & Exxon (Anchorage) & scott.a.cooley@exxonmobil.com & (907) 564-3776 & 3 \\
\hline Bob Crandall & AOGCC & bob crandall@admin.state.ak.us & $(907) 7931230$ & 1 \\
\hline Abhijit Dandekar & University of Alaska Fairbanks & ffayd@uaf.edu & $(907) 474-6427$ & 2 \\
\hline Scott Digert & BPXA - MPU & DigertSA@BP.com & (907) 564-4480 & 3 \\
\hline Kevin Frank & ConocoPhillips & & & 3 \\
\hline Bob Fisk & Bureau of Land Management & bfisk@ak.blm.gov & (907) 271-4407 & - \\
\hline Ken Griffin & Alaska - Division of Oil and Gas & kwg@dnr.state.ak.us & (907) 269-8820 & 2 \\
\hline Steve Hancock & APA Engineering & SHancock@apa-inc.com & (281) 872-9904 & 2 \\
\hline Mary Harvick & Alaska - Division of Oil and Gas & mih@dnr.state.ak.us & (907) 269-8808 & 2 \\
\hline James Hemsath & Department of Energy & James.Hemsath@NETL.DOE.GOV & (907) 452-2672 & 3 \\
\hline Bruce Herman & Mineral Management Service & bruce.herman@mms.gov & (907) 334-5326 & 1 \\
\hline James Howard & ConocoPhillips & James.J.Howard@conocophillips.com & (918) 661-9575 & 1 \\
\hline Bob Hunter & ASRC Energy Services & robert.hunter@asrcenergy.com & (907) 339-6377 & 2 \\
\hline Don Ince & ConocoPhillips & don.ince@ConocoPhillips.com & (907) 265-6298 & 3 \\
\hline Kim Juenger & ConocoPhillips & Kim.Juenger@conocophillips.com & (281) 293-5716 & 3 \\
\hline Bob Kleinberg & Schlumberger Research & Kleinberg@slb.com & (203) $431-5410$ & 1 \\
\hline Ryan Kurasaki & Hawaii Natural Energy Institute & rkurasak@hawaii.edu & (808) 956-5604 & 3 \\
\hline Carrie Lauden & Schlumberger Info Solutions & CMLaudon@anchorage.oilfield.slb.com & (907) 273-1700 & 1 \\
\hline Beth Maclean & Bureau of Land Management & Beth Maclean@blm.gov & (907) 267-1448 & 3 \\
\hline Pete McGrail & Pacific NW Laboratory Battelle & Pete.mcgrail@PNL.gov & (509) 376-9193 & 2 \\
\hline Mark Myers & Alaska - Division of Oil and Gas & mdm@dnr.state.ak & (907) 269-8817 & 3 \\
\hline Dave Nyland & Alaska - Division of Oil and Gas & dln@dnr.state.ak & (907) 269-0137 & 3 \\
\hline Daniel Palmer & Schlumberger Alaska & palmer2@anchorage.oilfield.slb.com & $((907)$ 273-1700 & 2 \\
\hline Shirish Patil & University of Alaska Fairbanks & ffslp@uaf.edu & (907) 474-5127 & 3 \\
\hline Brenda Pierce & United States Geological Survey & bpierce@usgs.gov & (703) 648-6421 & 3 \\
\hline Pulak Ray & Mineral Management Service & pulak.ray@mms.gov & (907) 787-1511 & 1 \\
\hline Richard Sigal & University of Oklahoma & rsigal@ou.edu & (405) 325-6799 & 1 \\
\hline Pete Stokes & PRA & pstokes@petroak.com & (907) 2721232 & 3 \\
\hline Bob Swenson & Alaska DGGS & robert swenson@dnr.state.ak.us & (907) 748-8905 & 3 \\
\hline Charles Thomas & SAIC & charles.thomas@saic.com & $(907) 271-1550$ & 2 \\
\hline
\end{tabular}




\begin{tabular}{|c|c|c|c|c|}
\hline John Tichotsky & Alaska Cambridge Group & ¡tichotsky@alaska.com & (907) 440-4701 & 3 \\
\hline Arlon Tussing & $\begin{array}{l}\text { Institute of Social and Economic } \\
\text { Research }\end{array}$ & arlontussing@comcast.net & (206) 275-0665 & 3 \\
\hline Fran UImer & $\begin{array}{l}\text { Institute of Social and Economic } \\
\text { Research }\end{array}$ & ayiser@uaa.alaska.edu & $((907) 786-5402$ & 3 \\
\hline Tom Walsh & PRA & tom@petroak.com & (907) 2721232 & 1 \\
\hline Douglas Waters & Arctic Slope Regional Corporation & Doug.Waters@asrcenergy.com & (907) 339-6000 & \\
\hline Jane Williamson & AOGCC & jane williamson@admin.state.ak.us & (907) 793-1226 & 2 \\
\hline Scott Wilson & Ryder Scott & Scott.Wilson@Denver.RyderScott.com & (303) 339-8123 & 2 \\
\hline Tao Zhu & University of Alaska Fairbanks & fftz@uaf.edu & (907) 474-5141 & 2 \\
\hline
\end{tabular}




\section{ALASKA GAS HYDRATE PLANNING WORKSHOP -WORKSHOP PROCEEDINGS-}

\section{LIST OF ELECTRONIC PRESENTATIONS}

This workshop included a series of organizational and technical review presentations as described in the agenda. Electronic copies of the presentations (as listed below) and a copy of this report can be found on the following web site http://www.dggs.dnr.state.ak.us/AlaskaGasHydrates.htm

- Mark D. Myers, Alaska Division of Oil and Gas; Introduction \& Unlocking Alaska's Natural Gas Hydrates: State of Alaska Perspective <Mark Myers Intro_State of Alaska Perspective.pdf>

- Ray Boswell, United States Department of Energy; U.S. Department of Energy Gas Hydrate Program and Perspective < Ray Boswell DOE Gas Hydrate Program.pdf $>$

- Tim Collett, U.S. Geological Survey; Historical Review through Current Programs Assessments and Prospecting <Tim Collett Historical Review.pdf>

- Robert Hunter, ASRC Energy Services; USDOE-BPXA Collaborative Research Project Update - Production Modeling and Resource Evaluation $<$ Robert Hunter DNR-BPXADOE-Project.pdf>

- Shirish Patil, University of Alaska, Fairbanks; Gas Hydrates Research Review < Shirish Patil UAF Gas Hydrates Research Review.pdf>

- Scott Digert, British Petroleum Exploration (Alaska); Industry Perspectives - Historical Background and Current Interest $<$ Scott Digert BP Hydrates Perspective.pdf $>$

- Andre Bouchard, ConocoPhillips Alaska; Industry Perspectives - Historical Background and Current Interest < Andre Brouchard ConocoPhillips Perspectives.pdf >

- Steve Hancock, APA; Industry Perspectives - Historical Background and Current Interest $<$ Steve Hancock Hydrate Production Issues.pdf> 


\section{List of Acronyms and Abbreviations:}

$\begin{array}{ll}\text { ADOG } & \text { Alaska Division of Oil and Gas } \\ \text { ADGGS } & \text { Alaska Division of Geological and Geophysical Surveys } \\ \text { ANS } & \text { Arctic (Alaska) North Slope } \\ \text { AOGCC } & \text { Alaska Oil and Gas Conservation Commission } \\ \text { ASRC } & \text { Artic Slope Regional Corporation } \\ \text { BLM } & \text { Bureau of Land Management } \\ \text { BPXA } & \text { British Petroleum Exploration (Alaska) } \\ \text { CPA } & \text { ConocoPhillips Alaska } \\ \text { DTS } & \text { Distributed Temperature Survey } \\ \text { GKA } & \text { Greater Kuparuk Area } \\ \text { ISER } & \text { Institute of Social and Economic Research } \\ \text { KRU } & \text { Kuparuk River Unit } \\ \text { LWD } & \text { Logging While Drilling } \\ \text { MDT } & \text { Modular Dynamic Tester } \\ \text { MPU } & \text { Milne Point Unit } \\ \text { MMS } & \text { Mineral Management Service } \\ \text { NMR } & \text { Nuclear Magnetic Resonance } \\ \text { ODP } & \text { Ocean Drilling Program } \\ \text { PBU } & \text { Prudhoe Bay Unit } \\ \text { PCP } & \text { Progressive cavity pumps } \\ \text { RFT } & \text { Repeat Formation Tester } \\ \text { UAF } & \text { University of Alaska, Fairbanks } \\ \text { USDOE } & \text { U.S. Department of Energy } \\ \text { USGS } & \text { U.S. Geological Survey } \\ \text { Vp } & \text { Compressional-wave velocity } \\ \text { Vs } & \text { Shear-wave velocity } \\ \text { VSP } & \text { Vertical Seismic Profile } \\ \text { XRD } & \text { X-ray refraction } \\ \text { 2D } & \text { Two dimensional (seismic survey) } \\ \text { 3D } & \text { Three dimensional (seismic survey) } \\ & \end{array}$

